\title{
Use of immature seed germination and single seed descent for rapid genetic gains in pigeonpea
}

\author{
Kulbhushan Saxena | Rachit K. Saxena | Rajeev K. Varshney
}

International Crops Research Institute for the Semi-Arid Tropics, Patancheru, India

\section{Correspondence}

Kulbhushan Saxena and Rachit K. Saxena, International Crops Research Institute for the Semi-Arid Tropics, Patancheru, India. Emails: kbsaxena1949@gmail.com; r. saxena@cgiar.org

Communicated by: M. Prasad

\begin{abstract}
Long duration required for generation advancement in pigeonpea [Cajanus cajan (L.) Millsp] is one of the major bottlenecks in realizing rapid genetic gains. Therefore, a technology for rapid generation turnover is warranted to facilitate the development of new cultivars and recombinant inbred lines. Breeding of early-maturing cultivars has now opened up the possibility of rapid generation advance (RGA) in this crop. This paper reports the development of an RGA technology that integrates the germination of immature seeds with single seed descent method of breeding. The results showed that immature 35 -day-old seeds can be used successfully to turn over a generation of pigeonpea with $100 \%$ seed germination. These way $3 / 4$ successive generations can be grown within a year. The methodology presented in this study will accelerate the breeding process for breeding cultivars and develop rapidly the materials required for genomics research in pigeonpea.

KEYWORDS

immature seed germination, pigeonpea, rapid generation advance, rapid genetic gain, single seed descent method
\end{abstract}

\section{1 | INTRODUCTION}

Greater genetic gain is the most important activity of any breeding programme and traditionally it is a time-consuming process primarily due to long time required for the advancement of 6-7 generations to select desirable recombinants from a cross. To save time and resources in pure-line breeding, some alternative approaches were suggested. For instance, Goulden (1941) proposed the advancement of $F_{2}$ population rapidly without selection up to homozygous stage. In each generation, the conservation of genetic variability was ensured by harvesting a representative single seed from every plant of the population. Brim (1966) called it a "modified pedigree method." In some annual crops, the use of an off-season nursery for generation advance is a good option; but in pigeonpea [Cajanus cajan (L.) Millsp.] a seed-to-seed generation takes almost a year and breeding of cultivars takes almost a decade. This is primarily due to its strict requirement of short $(<10 \mathrm{~h})$ days for the induction of flowering. Thus, an off-season generation advance is not possible. With the advent of early-maturing (90-120 days) pigeonpea germplasm, the rapid generation advancement has become a possibility. The present study discusses the scope and opportunities for rapid generation advancement in pigeonpea by integrating together the germination of immature seeds and single seed descent method of breeding.

\section{2 | MATERIALS AND METHODS}

Four early-maturing cultivars ICPLs 00004, 00151, 85024 and 97093 were selected for this study. Two experiments were conducted in a glasshouse under natural photoperiods with mean day and night temperatures maintained approximately at $32^{\circ} \mathrm{C}$ and $23^{\circ} \mathrm{C}$, respectively. Relative humidity in the glasshouse was maintained at around $60 \%$. These experiments were conducted in plastic pots of $25 \mathrm{~cm}$ diameter, filled with a mixture of three alfisols: 1 farm yard manure. In each pot, 8-10 seeds were sown, approximately $3 \mathrm{~cm}$ deep in the soil. The watering was done twice a week. Fifteen days after sowing, four seedlings were retained in each pot.

The first experiment with two replications was designed to determine the appropriate pod age for harvesting. To impose various 
harvesting treatments, in each cultivar over 150 freshly opened flowers were tagged individually with a small piece of wool on a single day and 10-16 growing pods were harvested each on 21st, 28th, and 35th days after tagging. The shelled seeds were treated with fungicide and immediately sown in a new set of pots. The germination in each pot was recorded 15 days after sowing and arcsinetransformed data were analysed in a spilt plot design, considering harvests as main plots and varieties as subplots.

The second experiment was conducted to study the possibility of advancing multiple generations per year using the germination of immature seeds. This experiment began in the middle of June and continued for full 1 year. Limited glasshouse space did not permit replications. In this experiment also, the flower buds were tagged and the immature pods were harvested between 25 and 30 days after tagging. The shelled seeds were treated with fungicide and sown immediately in another set of pots. In each generation, data were recorded on germination (\%) and dates of flowering and harvesting of pods.

\section{3 | RESULTS}

In experiment 1, significant varietal differences were observed for germination, when pods were harvested on 21st day (Table 1). Cultivars ICPL 00151 (2\%) and ICPL 85024 (15\%) recorded poor germination on 21st day, which improved to over $95 \%$ in the 28th day of sampling and $100 \%$ in 35th day of sampling. ICPL 00004 (78\%) and ICPL 87093 (89\%) recorded almost identical germination in 21-dayold seeds and in the subsequent two harvests (Table 1).

To develop the technology of immature seed germination with high germination, the second experiment was conducted. The first generation of ICPL 85024, which flowered in 50 days and the pods were harvested in another 28 days, was completed in only 78 days (Table 2). In the second generation, the pods were harvested in 68 days. The third and fourth generations took over 80 days to complete. Thus from June 15 to May 9, four generations were taken within 313 days. In ICPL 87093, four successive generations were completed in 338 days. The other two cultivars took additional 16-

TABLE 1 Germination (\%) of developing seeds in four pigeonpea cultivars grown in a glasshouse

\begin{tabular}{lccc} 
& \multicolumn{2}{c}{ Days after flowering } \\
\cline { 2 - 4 } Cultivar & 21 & 28 & 35 \\
ICPL 4 & 78 & 100 & 100 \\
ICPL 151 & 2 & 96 & 100 \\
ICPL 85024 & 15 & 98 & 100 \\
ICPL 87093 & 89 & 100 & 100 \\
Mean & 46.0 & 98.5 & 100.0 \\
SE for variety means & & \pm 2.21 & \\
SE for harvest dates & & \pm 2.13 & \\
SE for var. within harvest & & \pm 4.78 & \\
SE for var. in diff harvests & & \pm 4.94 & \\
\hline
\end{tabular}

34 days for turning out the same number of generations (Table 2). From the experiment 1 , it was visualized that delaying the pod harvest to 35 th of day, $100 \%$ germination (Table 1) was achieved. Hence, with perfect germination three seed-to-seed generations can be advanced within a year; and to take four generations about 400 days will be required. On average, the September sowings took the least time (53 days) to flowering due to shortening days, suggesting that none of the genotypes used in this study was truly insensitive to photoperiod.

\section{4 | DISCUSSION}

A typical pedigree breeding method is based on premise that the progress in selection and advancement of population can be achieved simultaneously. Hence in every generation, the segregating population needs to be grown in such an environment where the genetic differences for key traits would express properly; and this would consume more resources in terms of time and money. To speed up the breeding process, Goulden (1941) proposed rapid inbreeding of segregating populations without selection; and for conserving the genetic variability, it was integrated with single seed descent method of breeding. In pigeonpea, so far the rapid generation turnover has not been used in the breeding programmes due to constraints such as longer maturity and photosensitivity. However, the recent success in breeding early-maturing genetic materials offers an opportunity for using this approach in breeding pigeonpea cultivars.

The fertilized egg cells undergo various morphological, physiological and functional changes before they reach the seed maturity stage (Delouche, 1973). According to Singh, Jambunathan, \& Narayanan (1980), the rapid starch accumulation in pigeonpea occurs between 14 and 28 days after flowering, while the soluble sugars continue to increase up to 35th day, but the most amino acids and minerals accumulate in the first seven days. Balkrishanan, Vanangamudi, \& Natarajaratnam (1984) reported no germination in 7- and 14-day-old pigeonpea seeds. They recorded $50 \%$ seed germination in 21 days, which further increased to $70 \%$ on 35 th day and $72-88 \%$ at seed maturity. The results of present study were not in full agreement with those of Balkrishanan et al. (1984), but the trends in both studies were more or less similar. The dry weights in developing seeds steadily increased between 28 and 35 days from flowering and it suggested that for seed germination the key factor was food reserves, which provide instant energy for germination and early seedling growth.

In the present study, the seed germination in the 28th day harvested lots varied from 81.5 to $86.7 \%$, and this was not up to the mark as $15-20 \%$ of the population will be lost and it will adversely affect the retention of genetic variability of the cross. From breeders' points of view also, this situation is unacceptable and it is against the philosophy of single seed descent method of breeding. The seeds harvested 35 days after flowering yielded $100 \%$ germination (Table 1) and this suggested that for achieving good results through breeding, the harvesting of pods should be delayed by another week. The breeders, however, considering the importance of 
TABLE 2 Summary of generation turnover in four earlymaturing pigeonpea genotypes

\begin{tabular}{|c|c|c|c|c|c|c|c|c|}
\hline \multirow[b]{2}{*}{ ICPL No. } & \multirow{2}{*}{$\begin{array}{l}\text { Generation } \\
\text { number }\end{array}$} & \multicolumn{3}{|l|}{ Date of } & \multicolumn{3}{|l|}{ Days } & \multirow[b]{2}{*}{ Germ. (\%) } \\
\hline & & Sowing & Flowering & Harvesting & Flowering & Pod age & Cumulative & \\
\hline \multirow[t]{5}{*}{85024} & 1 & 15 June & 4 Aug & $1 \mathrm{Sep}$ & 50 & 28 & 78 & 83.3 \\
\hline & 2 & 9 Sep & 24 Oct & $17 \mathrm{Nov}$ & 43 & 25 & 146 & 81.5 \\
\hline & 3 & $17 \mathrm{Nov}$ & 15 Jan & $10 \mathrm{Feb}$ & 59 & 26 & 231 & 86.7 \\
\hline & 4 & 16 Feb & $14 \mathrm{Apr}$ & 9 May & 57 & 25 & 313 & 72.7 \\
\hline & Mean & & & & 52.3 & 26.0 & - & 81.05 \\
\hline \multirow[t]{5}{*}{87093} & 1 & 15 June & 4 Aug & $1 \mathrm{Sep}$ & 55 & 28 & 78 & 100.0 \\
\hline & 2 & 9 Sep & $1 \mathrm{Nov}$ & $26 \mathrm{Nov}$ & 53 & 25 & 161 & 95.0 \\
\hline & 3 & $26 \mathrm{Nov}$ & 29 Jan & $24 \mathrm{Feb}$ & 64 & 26 & 251 & 80.0 \\
\hline & 4 & $26 \mathrm{Feb}$ & $27 \mathrm{Apr}$ & 24 May & 60 & 27 & 338 & 100.0 \\
\hline & Mean & & & & 56.8 & 26.5 & - & 93.7 \\
\hline \multirow[t]{5}{*}{00004} & 1 & 15 June & 15 Aug & $10 \mathrm{Sep}$ & 61 & 26 & 87 & 90.0 \\
\hline & 2 & $16 \mathrm{Sep}$ & $11 \mathrm{Nov}$ & $11 \mathrm{Dec}$ & 56 & 30 & 173 & 96.0 \\
\hline & 3 & $15 \mathrm{Dec}$ & $17 \mathrm{Feb}$ & $15 \mathrm{Mar}$ & 64 & 28 & 265 & 80.0 \\
\hline & 4 & $20 \mathrm{Mar}$ & 15 May & 11 June & 57 & 27 & 349 & 100.0 \\
\hline & Mean & & & & 59.5 & 27.8 & - & 91.5 \\
\hline \multirow[t]{5}{*}{00151} & 1 & 15 June & 12 Aug & $16 \mathrm{Sep}$ & 58 & 35 & 93 & 96.0 \\
\hline & 2 & $16 \mathrm{Sep}$ & $15 \mathrm{Nov}$ & $14 \mathrm{Dec}$ & 60 & 29 & 182 & 85.0 \\
\hline & 3 & $15 \mathrm{Dec}$ & $20 \mathrm{Feb}$ & $20 \mathrm{Mar}$ & 67 & 28 & 277 & 86.2 \\
\hline & 4 & $20 \mathrm{Mar}$ & 20 may & 17 June & 52 & 28 & 367 & 100.0 \\
\hline & Mean & & & & 61.8 & 30.0 & - & 98.80 \\
\hline
\end{tabular}

the population and the key traits, can decide on sacrificing either the time from 35 to 28 days after flowering or the population size. But in order to have maximum segregation, the loss of population in $F_{2}$ generation will not be an ideal approach. Alternatively, they can also use a combination of harvesting times in different advancing generations.

The varietal difference in seed germination rate could arise due to genetic differences in the two key processes responsible for the growth and development of growing seeds. These include the rate of cell division and their expansion that is controlled by auxin signalling (Quint \& Gray, 2006); and the rate and amount of starch accumulation in the first 35 days, which directly influence the energy generation (Singh et al., 1980) and seed germination (Rao \& Rao, 1975). The study also revealed that for rapid generation advance in pigeonpea, earliness of the genotypes is a key factor. The process of generation advancement can be enhanced further by forcing the immature seeds to germinate, and for best results, the pods should be retained on plants for at least 35 days from flowering. Further, to conserve the highest level of genetic variability, the constraints such as seed dormancy, differences in growth rates of the growing seeds, appropriate harvesting time and maintenance of good plant health need to be addressed adequately. With "super early" (<90 days) genotypes being available now (Vales et al., 2012), even five generations within a year can be envisaged; and this will be a tremendous gain in terms of time required for breeding inbred cultivars.
In general, pigeonpea plants grow well within the temperature range of $20^{\circ}$ to $40^{\circ} \mathrm{C}$. The generation advancement under natural conditions should be limited to areas where the ambient temperatures remain within this limit; otherwise raising the off-season crop would require controlled temperature facilities. Besides breeding inbred cultivars, the pigeonpea breeders can also utilize this technology in developing various mapping populations for the traits of interest in a shortest possible time.

The traditional pure-line pigeonpea breeding programmes are resource intensive due to the limitations posed by growing a single crop per year; and therefore, raising an off-season nursery is also not feasible due to their strict short-day requirement for floral induction. The advent of early-maturing cultivars has opened up a possibility for growing successive multiple generations per year. In the present study, it has been demonstrated that $3 / 4$ generations can be advanced within a year. This can be achieved using the proposed technology that uses the germination of immature seeds and single seed descent method of breeding. This approach is expected to conserve time and resources and achieve the enhanced rate of genetic gains in breeding programmes and deliver the new pigeonpea cultivars to farmers in shortest possible time.

\section{ORCID}

Rachit K. Saxena (DD http://orcid.org/0000-0002-9405-3570 


\section{REFERENCES}

Balkrishanan, K., Vanangamudi, K. M., \& Natarajaratnam, N. (1984). Seed development and maturation studies in pigeonpea. Madras Agricultural Journal, 71, 387-390.

Brim, C. A. (1966). A modified pedigree method of selection in soybeans. Crop Science, 6, 2220.

Delouche, J. C. (1973). Seed maturation. In Seed production manual (pp. 162-165). New Delhi: NSC and Rockefeller Foundation.

Goulden, C. H. (1941). Problems in plant selection. 7th International Congress Genetics. 1039: 132-133.

Quint, M., \& Gray, W. M. (2006). Auxin signalling. Current Opinion in Plant Biology, 9, 448-453.

Rao, M. K. V., \& Rao, G. R. (1975). Growth, respiration and endogenous auxins on developing and germinating seeds of pigeonpea (Cajanus indicus Spreng). Seed Research, 3, 1-10.
Singh, U., Jambunathan, R., \& Narayanan, A. (1980). Biochemical changes in developing seeds of pigeonpea (Cajanus cajan). Phytochemistry, 19, 1291-1295.

Vales, M. I., Srivastava, R. K., Sultana, R., Singh, S., Singh, I., Singh, G., .. Saxena, K. B. (2012). Breeding for earliness in pigeonpea: Development of new determinate and non-determinate lines. Crop Science, 52, 2507-2516.

How to cite this article: Saxena K, Saxena RK, Varshney RK. Use of immature seed germination and single seed descent for rapid genetic gains in pigeonpea. Plant Breed. 2017;00:1-4. https://doi.org/10.1111/pbr.12538 